\title{
Reform des Jugendstrafrechts „Vorwärts, Rückwärts, Stop«
}

\author{
Bernd-Rüdeger Sonnen
}

Auf ihrer Herbstkonferenz befürworteten die JustizministerInnen der Länder mehrheitlich Vorschläge einer Gegenreform: »Klarstellung « der grundsätzlichen Anwendung des allgemeinen Strafrechts auf Heranwachsende (ZRP 2003, 479), damit auch die Möglichkeit der vorbehaltenen Sicherungsverwahrung (inzwischen Gesetz vom 27.12.2003 - BGBl I S. 3007; vgl. Frommel in diesem Heft), Erhöhung des Höchstmasses der Jugendstrafe von 10 auf 15 Jahre bei ausnahmsweiser Anwendung des Jugendstrafrechts auf junge Volljährige und die Einführung des sog. Warnschussarrestes vor jeder Form der Bewährung. Die Kritik an diesen Vorschlägen war deutlich: überholte Vorstellungen von Strafe und Sühne, ein Erziehungsideal des 19. Jahrhunderts (»schwarze Pädagogik«) und tiefes Misstrauen gegenüber einer engagierten Jugendgerichtsbarkeit.

»Vorwärts, Rückwärts, Stop « - so das Motto einer Jubiläumsveranstaltung aus Anlass des 50. Geburtstages des JGG, 1953 - trifft die aktuelle Situation: Reformansätze werden durch Gegenreformen blockiert. Schon das 1. JGG ÄndG 1990 ging von einem weiteren und grundlegenden Reformbedarf aus: z.B. Aufwertung des Täter-Opfer-Ausgleichs und klare Regelungen zur strafrechtlichen Behandlung Heranwachsender, zum Verhältnis der Erziehungsmaßregeln und Zuchtmitteln, den Voraussetzungen einer Jugendstrafe.

Zwar plädierte die Justizministerkonferenz auch für eine späte Entnazifizierung des JGG durch Streichung der Begriffe »Zuchtmittel« und "schädliche Neigungen", um sich dann aber der Heranwachsenden-Problematik mit der Behauptung zuzuwenden, nach dem Willen des historischen Gesetzgebers sollten Straftaten von Heranwachsenden in der Regel nach allgemeinem Strafrecht geahndet werden (wiederholt im BR-Entwurf eines Gesetzes zur Verbesserung der Bekämpfung der Jugendkriminalität BT-Drs. 15/1472 vom 06.08.2003).

Dies ist jedoch unrichtig. Der Gesetzgeber wollte ausweislich der Protokolle gerade kein Regel-Ausnahme-Verhältnis zu Gunsten des allgemeinen Strafrechts, sondern eine Prüfung im jeweiligen Einzelfall (so auch BGH StV 2003, 460). Es ist daher zu begrüßen, dass diese Tatsache nunmehr in der Antwort der Bundesregierung vom 27.11.2003 auf eine kleine Anfrage eindeutig klargestellt worden ist (BT-Drs. 15/2102, 2). Argumente für die (vollständige) Einbeziehung der Heranwachsenden in das Jugendstrafrecht sind die heute bis in das dritte Lebensjahrzehnt hineinreichenden Prozesse sozialer Reife und der Übernahme neuer Rollen in Ausbildung, Beruf und Partnerschaft. Auch das Problem der Gleichbehandlung wäre damit gelöst. Übrigens empfiehlt inzwischen auch der Europarat, im Hinblick auf die verlängerte Adoleszenzphase unter bestimmten Voraussetzungen junge Erwachsene unter 21 Jahren wie Jugendliche zu behandeln und den differenzierten Interventionsmöglichkeiten zu unterwerfen (Ministerkomitee am 24.09.2003). In der schon genannten Bundesrats-Initiative vom 06.08.2003 heißt es unter der Überschrift »Kosten«, dass durch die vermehrte Anwendung des allgemeinen Strafrechts auf Heran- wachsende und die Einführung des Warnschussarrestes tendenziell von einer spürbaren Mehrbelastung des Straf- und Jugendarrestsvollzuges auszugehen ist. »Diese wird jedoch durch die bessere spezial- und generalpräventive Wirksamkeit der Sanktionen zumindest teilweise aufgefangen werden «.

Demgegenüber war in der Begründung zum geltenden 1. JGG ÄndG 1990 an erster Stelle auf kriminologische Erkenntnisse verwiesen und dargelegt worden, dass und warum die in der Praxis erprobten neuen ambulanten Maßnahmen (Betreuungsweisung, sozialer Trainingskurs, Täter-Opfer-Ausgleich) die traditionellen Sanktionen (Geldauflage, Jugendarrest, Jugendstrafe) weitgehend

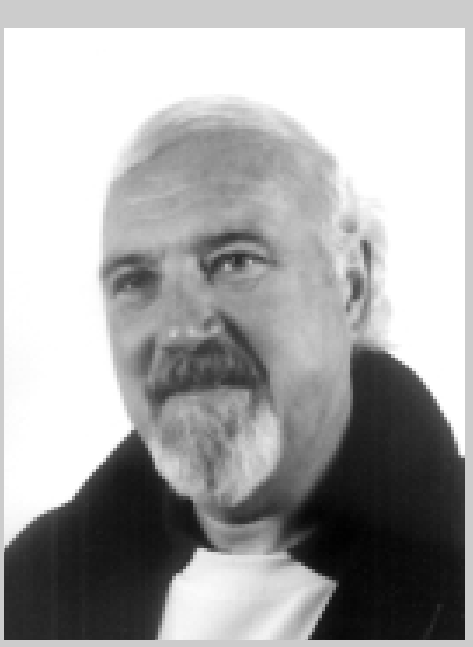

Bernd-Rüdeger Sonnen, Vorsitzender der DVJJ ersetzen können, ohne dass sich damit die Rückfallgefahr erhöht. "Schließlich ist seit langem bekannt, dass die stationären Sanktionen des Jugendstrafrechts (Jugendarrest und Jugendstrafe) sowie die Untersuchungshaft schädliche Nebenwirkungen für die jugendliche Entwicklung haben können« (BT-Drs. 11/5829, 1). Die Einschätzungen zur Wirksamkeit jugendstrafrechtlicher Sanktionen widersprechen sich also deutlich. Wer das Jugendstrafrecht reformieren möchte, muss sich deswegen zunächst vergewissern, ob die genannten kriminologischen Erkenntnisse insbesondere der empirischen Sanktionsforschung heute noch (als Grundlage kriminalpolitischer Forderungen) Bestand haben. In seinem Gutachten zum 64. Deutschen Juristentag Berlin 2002 hat Hans-Jörg Albrecht eindrucksvoll den kriminologischen Erkenntnisstand national wie international aufbereitet und im Ergebnis die kriminologische Basis des geltenden Jugendstrafrechts für nach wie vor tragfähig bestätigt. Für die in der Bundesratsinitiative behauptete bessere spezial- und generalpräventive Wirksamkeit fehlt insoweit eine empirisch gesicherte kriminologische Grundlage. Um einer Gesamtreform des Jugendstrafrechts Konturen zu geben, sei auf den Abschlussbericht der 2. Jugendstrafrechtsreform-Kommission der DVJJ 2002 verwiesen. Die Vorschläge knüpfen an die kriminalpolitische Zielsetzung des geltenden 1. JGG ÄndG 1990 an und entwickeln sie unter der Berücksichtigung der Mindestgrundsätze der Vereinten Nationen für die Jugendgerichtsbarkeit 1985 behutsam fort. Die Vorschläge sind in den Grundsätzen von Empirie- und Folgenorientierung, von Rationalität und Humanität verpflichtet und verdienen schon deswegen, zumindest diskutiert zu werden. 